\title{
Rendezvous technique using bronchoscopy and gastroscopy to close a tracheoesophageal fistula by placement of an over-the-scope clip
}
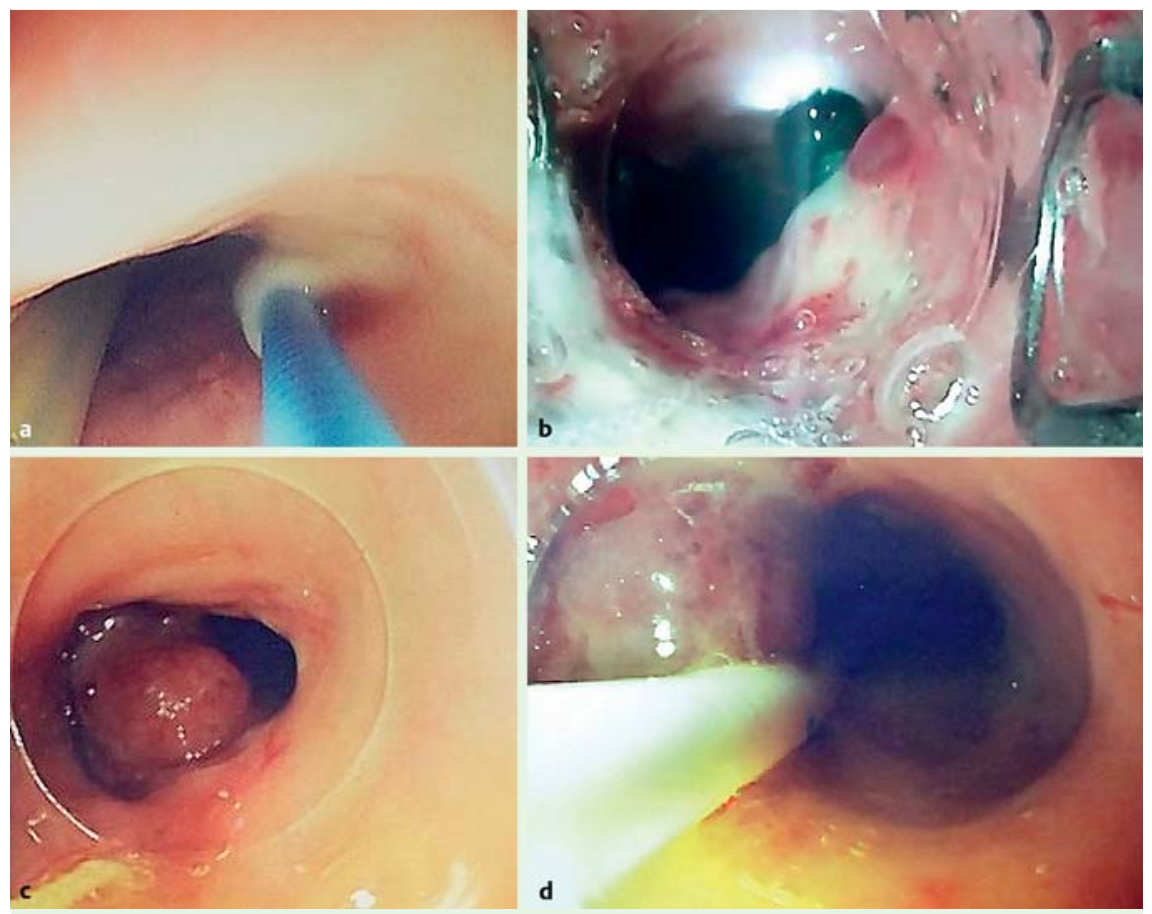

Fig. 1 Endoscopic views showing: a the suspected mucosal flap at the site of the tracheoesophageal fistula (TEF); $\mathbf{b}$ the rendezvous bronchoscope visible using the endoscope, previously loaded with an over-the-scope clip (OTSC) and positioned in the esophagus; $\boldsymbol{c}$ the OTSC placed at the esophageal opening of the TEF; $\mathbf{d}$ a feeding nasojejunal tube that was placed endoscopically at the end of the procedure.

A 23-year-old man with polytrauma was admitted to the intensive care unit for level 3 postoperative support. His medical history included VATER syndrome [1] with corrective surgery for the tracheoesophageal fistula (TEF). Ventilatory support according to ARDSNet criteria in the acute phase was complicated by a persistent air leak and significant gastric distension, raising the possibility of a residual TEF. An initial gastroscopy failed to show a fistulous opening. A Ryle's tube for gastric air drainage and nasojejunal tube for enteral feeding were left in situ. Flexible bronchoscopy through the endotracheal tube showed a flap with access to the esophagus from the bronchial tree just above the carina, confirming the clinical suspicion of a TEF.

At repeat endoscopy, the site of the communication was not immediately apparent but a mucosal flap was noted in the upper esophagus ( Fig.1a). We performed a rendezvous bronchoscopy and identified a $1-\mathrm{cm}$ fistulous opening in the esophagus at $26 \mathrm{~cm}$ from incisors ( Fig. 1 b). This was successfully closed using an over-thescope clip (OTSC; Ovesco, Tübingen, Germany) ( Fig.1c). The feeding nasojejunal tube was replaced endoscopically ( Fig.1d). Successful closure of the fistula was confirmed by the complete absence of air drainage from the Ryle's tube, improvement in the ventilatory mechanics, and by a Gastrografin swallow. The patient was subsequently weaned off the ventilator and extubated.

OTSCs are widely used for closure of perforations and fistulas [2,3]. Nonsurgical closure of a TEF by rendezvous bronchoscopy and gastroscopy performed simultaneously has not been reported previously. The fistulous opening of a TEF can usually be identified during gastro- scopy; however, in cases where the fistula is small and covered by a mucosal flap, as described here, a combined procedure can facilitate identification of the opening and direction of the fistula to aid accurate clip placement. This technique has the potential for use in closure of similar defects where a definitive surgical procedure would carry a high risk. In our case, the immediate requirement to enable adequate ventilation in a patient with an acute head injury was successfully achieved.

Endoscopy_UCTN_Code_TTT_1AO_2AI

Competing interests: None

\section{Sudheer Vinnamala, Buddhavarapu Murthy, Jitendra Parmar, Nikhil Bhasin, Pratima Verma, Colin Melville, Jayan Mannath}

University Hospitals Coventry and Warwickshire NHS Trust, Clifford Bridge Road, Coventry, UK

\section{References}

1 Quan L, Smith DW. The VATER association. Vertebral defects, Anal atresia, T-E fistula with esophageal atresia, Radial and Renal dysplasia: a spectrum of associated defects. J Pediatr 1973; 82: 104-107

2 Weiland T, Fehlker M, Gottwald T et al. Performance of the OTSC System in the endoscopic closure of gastrointestinal fistulae a meta-analysis. Minim Invasive Ther Allied Technol 2012; 21: 249-258

3 Weiland T, Fehlker M, Gottwald T et al. Performance of the OTSC System in the endoscopic closure of iatrogenic gastrointestinal perforations: a systematic review. Surg Endosc 2013; 27: 2258-2274

\section{Bibliography}

Dol http://dx.doi.org/

10.1055/s-0034-1377215

Endoscopy 2014; 46: E301

(c) Georg Thieme Verlag KG

Stuttgart · New York

ISSN 0013-726X

\section{Corresponding author}

\section{Jayan Mannath, MD}

Department of Gastroenterology

University Hospitals Coventry and Warwickshire NHS Trust

Clifford Bridge Road

Coventry

CV2 2DX

United Kingdom

jayanmannath@doctors.org.uk 